\title{
Measurement of the hypotenuse of the vertical optic nerve head cup with spectral-domain optical coherence tomography for the structural diagnosis of glaucoma
}

This article was published in the following Dove Press journal:

Clinical Ophthalmology

Fabio Lavinsky ${ }^{1,2}$

Camila Zanella Benfica ${ }^{2}$

Nédio Castoldi ${ }^{2}$

Anne Elise Cruz do Carmo

Chaves $^{2}$

Paulo Augusto de Arruda

Mello'

'Department of Ophthalmology, Paulista School of Medicine, São Paulo Hospital, Universidade Federal de São Paulo (UNIFESP), São Paulo, SP, Brazil; ${ }^{2}$ Department of Ophthalmology, Universidade Federal do Rio Grande do Sul (UFRGS), Porto Alegre, RS, Brazil
Correspondence: Fabio Lavinsky Instituto de Oftalomologia Lavinsky, Rua Quintino Bocaiuva 673, Porto Alegre,

RS, 904I0-|40, Brazil

Tel +555181528587

Fax +55 5I 33302444

Email lavafabiomed@gmail.com
Purpose: To evaluate the hypotenuse of the vertical optic nerve head cup (HVOC), measured using the length and depth of the cup obtained with enhanced depth imaging spectral-domain optic coherence tomography (SD-OCT), as a biomarker for glaucoma diagnosis.

Methods: This was a prospective cross-sectional study of patients with glaucoma and controls. SD-OCT was performed in all participants to assess average circumpapillary retinal nerve fiber layer (RNFL) thickness. A vertical B-scan of the optic nerve head (ONH) was obtained for HVOC measurement. The length and depth of the optic nerve cup formed the sides of a right triangle that were used to calculate the HVOC. Participants also underwent standard automated perimetry.

Results: One hundred and fifty-six eyes were divided into three groups: mean deviation (MD) $<-7 \mathrm{~dB}$ (60 eyes); $\mathrm{MD} \geq-7 \mathrm{~dB}$ (74 eyes); and healthy subjects ( 22 eyes). The mean (SD) HVOC in these groups was $1,419.8$ (347.2) $\mu \mathrm{m}, 1,234.6(258.8) \mu \mathrm{m}$, and 685.79 (315.4) $\mu \mathrm{m}$ $(P<0.01)$, respectively. In the secondary structure-function analysis, only discs with a vertical diameter of 1.51-2.00 mm were included (120 eyes). The HVOCs were divided into four percentile groups, with the following means: 940, 1,128, 1,390, and 1,662 $\mu \mathrm{m}$. There was a significant difference in MD between percentile groups 1 and $3(P<0.03), 1$ and 4 $(P<0.001), 2$ and $3(P<0.02)$, and 2 and $4(P<0.001)$. RNFL thickness differed among all percentile groups $(P<0.001)$.

Conclusion: HVOC may provide an additional morphometric biomarker for the structural evaluation of $\mathrm{ONH}$ remodeling in glaucoma.

Keywords: glaucoma diagnosis, optic nerve head, visual fields, ocular imaging

\section{Introduction}

The relationship between structural and functional damage is an important component of glaucoma diagnosis and management. ${ }^{1-3}$ The structural evaluation of the optic nerve head $(\mathrm{ONH})$, retinal nerve fiber layer (RNFL), and macula using optical coherence tomography (OCT) provides important clinical information and is a useful tool for the diagnosis of glaucoma and assessment of its progression. ${ }^{4-11}$

The development of spectral-domain OCT (SD-OCT) has improved test speed and resolution compared to time-domain OCT. ${ }^{12}$ Scan speeds between 29,000 and $70,000 \mathrm{~Hz}$ and an axial resolution of up to $2 \mu \mathrm{m}$ can be demonstrated. ${ }^{13,14}$ Other features used to improve image quality in some commercially available SD-OCT devices include the automated real time (ART) mode for image averaging, noise reduction, 
and an eye-tracking system that follows the saccades. ${ }^{15}$ Enhanced depth imaging (EDI) OCT described by Spaide et al was originally developed to visualize the full thickness of the choroid, but it has also been used to evaluate the lamina cribrosa (LC) and deep ONH structures. ${ }^{16-18}$ Swept source OCT (SS-OCT) is a novel technology that can reach even higher scan speed rates (up to $400 \mathrm{KHz}$ ) with increased penetration, emerging as a promising tool for the assessment of the choroid and LC. ${ }^{19}$

Notwithstanding the improvements in technology, the structural evaluation of glaucoma still includes important evidence-based clinical parameters, such as optic disc appearance and size, neuroretinal rim tissue, presence of hemorrhage, peripapillary atrophy, and cup-to-disc ratio (CDR). ${ }^{20-23}$ OCT may enable further evaluation of morphometric and topographic parameters of the $\mathrm{ONH}$, such as CDR, cup volume, rim area, and rim volume. ${ }^{24}$ The minimum rim area assessed by SD-OCT, based on the shortest distance from the Bruch's membrane opening (BMO) to the internal limiting membrane (ILM), has been correlated with RNFL thickness and visual field mean deviation (MD). ${ }^{25,26}$

Deep ONH structures, such as LC, as well as LC defects and posterior LC displacement can be evaluated using EDI SD-OCT. ${ }^{17,27-29}$ Posterior LC displacement has been demonstrated as an important histopathological hallmark of deformation of glaucomatous $\mathrm{ONH}$ in experimental glaucoma and in studies using postmortem glaucomatous eyes. ${ }^{30-32}$

The purpose of this study was to evaluate the hypotenuse of the vertical optic nerve head cup (HVOC) as a novel morphometric biomarker for the assessment of ONH using EDI SD-OCT. The vertical B-scan with the largest cup seen on infrared is used for HVOC measurement. The depth of the posterior LC displacement, measured from the BMO level, and the length of the vertical cup form the sides of a right triangle that are used to calculate the hypotenuse. The authors hypothesize that HVOC is a useful parameter for the quantitative evaluation of $\mathrm{ONH}$ remodeling in glaucoma.

\section{Methods}

The study was approved by the Ethics Committees of Hospital de Clínicas de Porto Alegre and Universidade Federal de São Paulo and was registered at Plataforma Brasil, the Brazilian national research directory (registration number: 53521916.2.3001.5505). Written informed consent was obtained from all participants. The study followed the tenets of the Declaration of Helsinki.

This was a prospective non-interventional cross-sectional study of patients evaluated for open-angle glaucoma at Hospital de Clínicas de Porto Alegre. All patients were evaluated according to an established clinical protocol that includes a broad review of medical history and a comprehensive ophthalmic examination.

\section{Participants}

Eligible participants were all patients with a diagnosis of glaucoma defined as the presence of characteristic optic disc and retinal changes, such as neuroretinal rim thinning, RNFL defect, localized notching, and splinter hemorrhage, and at least one intraocular pressure (IOP) measurement $>21 \mathrm{mmHg}$. Participants with ocular or systemic conditions that could affect the optic nerve or examination results were excluded. Exclusion criteria for glaucoma cases were cognitive impairment, eye diseases (including diabetic retinopathy and retinal vein occlusion), trauma, dense cataract, and previous ocular surgery that could influence the results of standard automated perimetry (SAP) or the measurements made with OCT. Poor-quality images with a Q score $<20$ were disqualified.

Patients with glaucoma were arbitrarily divided into two groups based on visual field MD: patients with an MD worse than $-7 \mathrm{~dB}$ and patients with an $\mathrm{MD} \geq-7 \mathrm{~dB}$, including those with optic disc findings characteristic of glaucoma and no SAP changes (preperimetric glaucoma).

Controls had an IOP between 10 and $21 \mathrm{mmHg}$, normal SAP, optic disc within normal limits, and normal appearing iridocorneal angles. Inclusion criteria for controls were age between 18 and 60 years, clear media, and good cooperation during examination. Exclusion criteria were an IOP $>21 \mathrm{mmHg}$, optic discs suspected of having glaucoma (with one of the following conditions: CDR $>0.5$, hemorrhage, or RNFL defect evaluated clinically), visual field defects meeting the Anderson criteria for glaucoma, and any previous ocular disease or ocular surgery.

\section{Study protocol}

Participants provided a detailed medical and ophthalmic history and underwent ophthalmic examination including slit-lamp biomicroscopy, IOP measurements using applanation tonometry, gonioscopy, and dilated fundus examination. All participants underwent SD-OCT (Spectralis OCT; Heidelberg Engineering GmbH, Dossenheim, Germany). The SD-OCT protocol included a $3.45-\mathrm{mm}$ circular scan to determine circumpapillary RNFL thickness. The 3.45-mm scan circle was then positioned manually at the center of the optic disc, and, using the image of the $\mathrm{ONH}$, a vertical B-scan was obtained with the EDI mode for HVOC measurement. The EDI mode places the zero delay at the bottom of the screen without inverting the images, thus enhancing 
visualization of deeper ONH layers. All participants also underwent SAP (Humphrey VF Analyzer, 24-2 SITAStandard strategy; Carl Zeiss Meditec AG, Jena, Germany). A SAP defect was defined as the presence of at least three contiguous points within the same hemifield on the pattern deviation plot at a $P<5 \%$ level and one of which is depressed at a $P<1 \%$ level, and a glaucoma hemifield test outside normal limits. Unreliable SAP measurements were disqualified. All included participants with glaucoma had previous SAP measurements. Perimetry and OCT were performed within a 3-month period.

\section{HVOC measurement}

HVOC was measured by an experienced examiner. For each patient, the vertical B-scan with the largest identifiable vertical cup on the infrared imaging mode of the SD-OCT device was selected for HVOC measurement. The eyetracking system was used to place the vertical line on the exact location selected by the examiner, and the ART mode was used for noise reduction. The 1:1 ratio was used to obtain B-scans. B-scans with a $\mathrm{Q}$ score $<20$ were disqualified. Measurements were made using the caliper provided by the software. The length and depth of the cup were measured and formed the sides of a right triangle that were used to calculate the HVOC. The first line, which was measured at the BMO level starting at the innermost portion of the descending RNFL tissue (ILM level) and connecting to the opposite side, represented the length of the cup. A second line starting at the former line and ending at the deepest portion of the anterior prelaminar tissue at the middle third of the cup represented the depth of the cup. The Pythagorean theorem was then used to calculate the hypotenuse of the triangle: $c^{2}=a^{2}+b^{2}$, where $c$ is the HVOC and $a$ and $b$ are the length and depth of the cup that represent the lengths of the two sides of the right triangle (Figure 1).

\section{Statistical analysis}

Baseline characteristics were compared using generalized estimating equations (GEE), which take into account

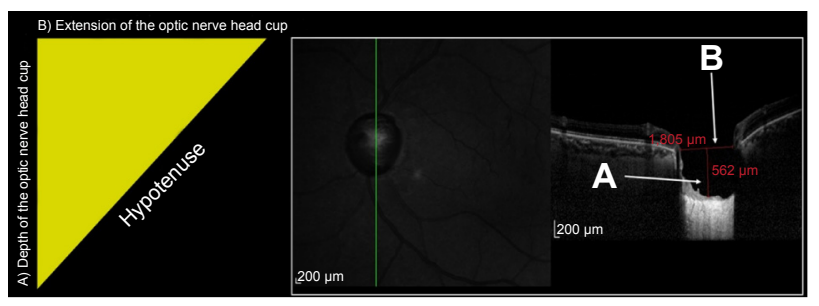

Figure I Measurement of the hypotenuse of the vertical optic nerve head cup using the depth (A) and length (B) of the cup as the sides of a right-angled triangle whose hypotenuse is calculated by the Pythagorean theorem.
Table I Demographic characteristics of study participants

\begin{tabular}{|c|c|c|c|}
\hline $\begin{array}{l}\text { Demographic } \\
\text { characteristics }\end{array}$ & $\begin{array}{l}\text { Group I: } \\
\text { glaucoma } \\
\text { MD }<-7 \mathrm{~dB} \\
(n=38)\end{array}$ & $\begin{array}{l}\text { Group 2: } \\
\text { glaucoma } \\
\text { MD } \geq-7 \mathrm{~dB} \\
(\mathrm{n}=44)\end{array}$ & $\begin{array}{l}\text { Group 3: } \\
\text { healthy } \\
\text { subjects } \\
(n=13)\end{array}$ \\
\hline \multicolumn{4}{|l|}{ Sex, n (\%) } \\
\hline Male & I3 (34.2) & I4 (3I.8) & $5(38.5)$ \\
\hline Female & $25(65.8)$ & $30(68.2)$ & $8(61.5)$ \\
\hline \multicolumn{4}{|l|}{ Ethnicity, n (\%) } \\
\hline African-Brazilians & $6(15.8)$ & $6(13.63)$ & $0(0)$ \\
\hline White & $30(79.0)$ & $38(86.6)$ & $12(92.3)$ \\
\hline Mixed & $2(5.2)$ & $0(0)$ & I (7.7) \\
\hline
\end{tabular}

Abbreviation: MD, mean deviation.

the correlation between both eyes of the same individual. A generalized linear model, with coefficients obtained by GEE, was used to correlate and compare variables. A $P$-value $<0.05$ was considered to be statistically significant. SPSS, version 22.0 (IBM Corporation, Armonk, NY, USA), was used for statistical analysis.

\section{Results}

ONH was evaluated using the EDI mode of the Spectralis OCT device in 156 eyes of 95 participants. Demographic data are summarized in Table 1. In the glaucoma group, mean (SD) age was 69.7 (9.8) years for patients with $\mathrm{MD}<-7 \mathrm{~dB}$ and 68.2 (10.1) years for patients with $\mathrm{MD} \geq-7 \mathrm{~dB}$. Mean (SD) age was 40.1 (14.2) years in the control group.

The global average RNFL thickness was significantly different between the three groups (Table 2; Figure 2) $(P<0.001)$.

The SAP MD mean was $-16.7 \mathrm{~dB}(6.8)$ and $-2.5 \mathrm{~dB}(2.0)$ for the glaucoma groups with $\mathrm{MD}<-7 \mathrm{~dB}$ and $\mathrm{MD} \geq-7 \mathrm{~dB}$, respectively, and $-1.7 \mathrm{~dB}(3.7)$ for controls $(P<0.01)$. The correlation between average RNFL thickness and MD in our population was $r=0.681(P<0.001)$.

\section{HVOC measurement}

The components of HVOC are described in Table 3. The values obtained for HVOC and the length of the cup were

Table 2 Global average and median circumpapillary RNFL thickness measured by SD-OCT

\begin{tabular}{|c|c|c|}
\hline $\begin{array}{l}\text { Groups (number } \\
\text { of eyes) }\end{array}$ & $\begin{array}{l}\text { Global average } \\
\text { RNFL } \pm \text { PD*, } \mu \mathrm{m}\end{array}$ & $\begin{array}{l}\text { Median (IQR), } \\
\mu \mathrm{m}\end{array}$ \\
\hline Group I: glaucoma & $62.0 \pm 3.3$ & $54.0(49.0 ; 75.8)$ \\
\hline \multicolumn{3}{|l|}{$M D<-7 d B(60)$} \\
\hline Group 2: glaucoma & $84.4 \pm 1.8$ & $85.0(74.0 ; 94.0)$ \\
\hline \multicolumn{3}{|l|}{$M D \geq-7 \mathrm{~dB}(74)$} \\
\hline Group 3: control (22) & $96.6 \pm 2.3$ & 97.0 (90.5; 102.0) \\
\hline
\end{tabular}




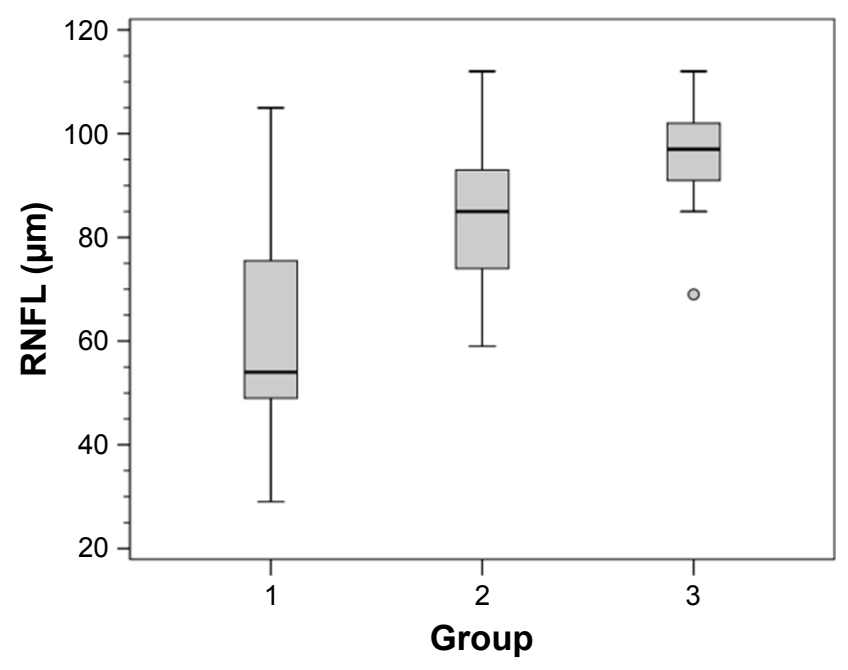

Figure 2 Box plot of average circumpapillary retinal nerve fiber layer (RNFL) thickness.

Notes: Group I: glaucoma mean deviation $<-7 \mathrm{~dB}(60)$; Group 2: glaucoma mean deviation $\geq-7 \mathrm{~dB}$ (74); Group 3: control (22).

significantly different between the three groups $(P<0.01)$, while the depth values were significantly different only between groups 1 and 3 and between groups 2 and 3 .

HVOC was also analyzed within the different vertical diameters of the optic disc: $<1.5 \mathrm{~mm}$ (Table 4); between 1.5 and $2.0 \mathrm{~mm}$ (Table 5); and $>2.0 \mathrm{~mm}$ (Table 6). A significant difference was found between the three groups in different optic disc diameters, except for groups 1 and 2 with an optic disc diameter $<1.5 \mathrm{~mm}$, which showed only a borderline significance (Figure 3).

\section{Structure-function correlation of HVOC with SAP MD and structure-structure correlation of HVOC with RNFL thickness}

The structure-function and structure-structure correlations of HVOC with SAP MD and RNFL thickness were analyzed using 120 eyes with an optic disc diameter between 1.5 and

Table 3 Mean extension and mean depth of the vertical optic nerve head cup and the hypotenuse between these values

\begin{tabular}{llll}
\hline $\begin{array}{l}\text { Groups (number } \\
\text { of eyes) }\end{array}$ & $\begin{array}{l}\text { Extension } \\
\text { (mean } \pm \text { PD), } \\
\mu \mathrm{m}\end{array}$ & $\begin{array}{l}\text { Depth } \\
(\text { mean } \pm \text { PD) }),\end{array}$ & $\begin{array}{l}\text { Hypotenuse } \\
(\text { mean } \pm \text { PD), } \\
\mu \mathrm{m}\end{array}$ \\
\hline $\begin{array}{l}\text { Group I: glaucoma } \\
\text { MD <-7 dB (60) }\end{array}$ & $\mathrm{I}, 323.7 \pm 322.9$ & $476.7 \pm 230.9$ & $\mathrm{I}, 419.8 \pm 347.2$ \\
$\begin{array}{l}\text { Group 2: glaucoma } \\
\text { MD } \geq-7 \mathrm{~dB}(74)\end{array}$ & $\mathrm{I}, 141.7 \pm 260.9$ & $451.3 \pm 157.9$ & $\mathrm{I}, 234.6 \pm 258.8$ \\
Group 3: control (2I) & $667.3 \pm 256.2$ & $225.43 \pm 150.8$ & $685.79 \pm 315.4$ \\
\hline
\end{tabular}

Note: ${ }^{a}$ Eyes with zero depth of optic nerve head cup $(n=1)$ were excluded from this analysis.

Abbreviations: $\mathrm{MD}$, mean deviation; $\mathrm{PD}$, pattern deviation.
Table 4 Mean (SE) of the hypotenuse of the vertical optic disc in nerves with vertical diameter $<1.5 \mathrm{~mm}$ and the significance between groups $(n=20)^{a}$

\begin{tabular}{|c|c|c|c|}
\hline $\begin{array}{l}\text { Groups (number } \\
\text { of eyes) }\end{array}$ & $\begin{array}{l}\text { Group I: } \\
\text { glaucoma MD } \\
<-7 \mathrm{~dB}(8)\end{array}$ & $\begin{array}{l}\text { Group 2: } \\
\text { glaucoma MD } \\
\geq-7 \mathrm{~dB}(8)\end{array}$ & $\begin{array}{l}\text { Group 3: } \\
\text { control (4) }\end{array}$ \\
\hline $\begin{array}{l}\text { Group I: glaucoma } \\
M D<-7 \mathrm{~dB}(8): \\
\text { I,I I } 2 \pm 9 \mid \mu \mathrm{m}\end{array}$ & - & 0.069 & $<0.001$ \\
\hline $\begin{array}{l}\text { Group 2: glaucoma } \\
M D \geq-7 \mathrm{~dB}(8): \\
906 \pm 68 \mu \mathrm{m}\end{array}$ & 0.069 & - & 0.014 \\
\hline $\begin{array}{l}\text { Group 3: control (4): } \\
393.4 \mathrm{I} \pm 136.04 \mu \mathrm{m}\end{array}$ & 0.001 & 0.014 & - \\
\hline
\end{tabular}

Note: ${ }^{S}$ Significance was calculated using generalized estimating equations. Abbreviations: MD, mean deviation; SE, standard error.

Table 5 Mean (SE) of the hypotenuse of the vertical optic disc in nerves with vertical diameter between 1.50 and $2.00 \mathrm{~mm}$ and the significance between groups $(n=\mid 20)^{a}$

\begin{tabular}{|c|c|c|c|}
\hline $\begin{array}{l}\text { Groups } \\
\text { (number } \\
\text { of eyes) }\end{array}$ & $\begin{array}{l}\text { Group I: } \\
\text { glaucoma MD } \\
<-7 \text { dB (49) }\end{array}$ & $\begin{array}{l}\text { Group 2: } \\
\text { glaucoma MD } \\
\geq-7 \text { dB (57) }\end{array}$ & $\begin{array}{l}\text { Group 3: } \\
\text { control (14) }\end{array}$ \\
\hline $\begin{array}{l}\text { Group I: glaucoma } \\
\text { MD <-7 dB (49): } \\
\text { I,449 } 444 \mu \mathrm{m}\end{array}$ & - & $<0.00 \mathrm{I}$ & $<0.001$ \\
\hline $\begin{array}{l}\text { Group 2: glaucoma } \\
\text { MD } \geq-7 \mathrm{~dB}(57): \\
\mathrm{I}, 228 \pm 34 \mu \mathrm{m}\end{array}$ & $<0.001$ & - & $<0.001$ \\
\hline $\begin{array}{l}\text { Group 3: control } \\
\text { (14): } 739 \pm 103 \mu \mathrm{m}\end{array}$ & $<0.001$ & $<0.001$ & - \\
\hline
\end{tabular}

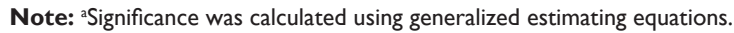
Abbreviations: MD, mean deviation; SE, standard error.

Table 6 Mean (SE) of the hypotenuse of the vertical optic disc in nerves with vertical diameter $>2.0 \mathrm{~mm}$ and the significance between groups $(n=16)^{a}$

\begin{tabular}{|c|c|c|c|}
\hline $\begin{array}{l}\text { Groups } \\
\text { (number } \\
\text { of eyes) }\end{array}$ & $\begin{array}{l}\text { Group I: } \\
\text { glaucoma MD } \\
<-7 \text { dB (3) }\end{array}$ & $\begin{array}{l}\text { Group 2: } \\
\text { glaucoma MD } \\
\geq-7 \text { dB (9) }\end{array}$ & $\begin{array}{l}\text { Group 3: } \\
\text { control (4) }\end{array}$ \\
\hline 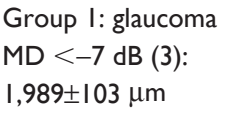 & - & $<0.001$ & $<0.001$ \\
\hline $\begin{array}{l}\text { Group 2: glaucoma } \\
M D \geq-7 \mathrm{~dB}(9): \\
I, 5 \mid 4 \pm 60 \mu \mathrm{m}\end{array}$ & $<0.001$ & - & $<0.001$ \\
\hline $\begin{array}{l}\text { Group 3: control } \\
\text { (4): } 857 \pm 53 \mu \mathrm{m}\end{array}$ & $<0.001$ & $<0.001$ & - \\
\hline
\end{tabular}

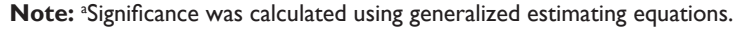
Abbreviations: MD, mean deviation; SE, standard error.

$2.0 \mathrm{~mm}$. The correlation of HVOC with MD was $r=-0.47$ $(P<0.001)$ (length of the cup: $r=-0.539$; depth of the cup: $r=-0.131)$ (Figure 4). The correlation of HVOC with RNFL thickness was $r=-0.64(P<0.001)$ (Figure 5). 


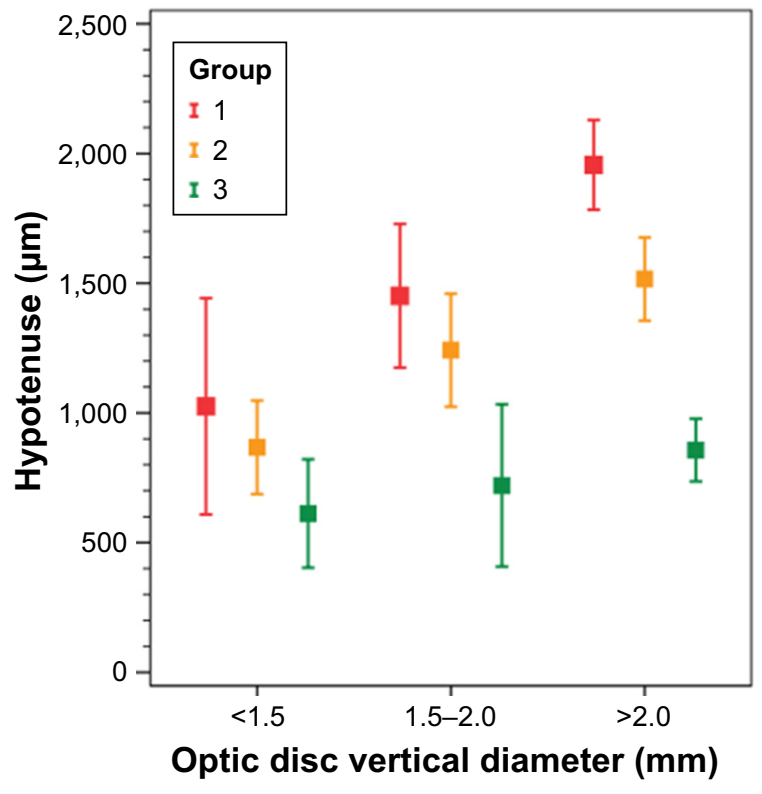

Figure 3 Box plot of the mean hypotenuse of the vertical optic nerve head cup for glaucoma groups and controls in different vertical diameters of the optic disc. Notes: Group I: glaucoma mean deviation $<-7 \mathrm{~dB}(60)$; Group 2: glaucoma mean deviation $\geq-7 \mathrm{~dB}$ (74); Group 3: control (2I)

The 120 eyes were further divided into four percentile groups according to their HVOC value. The mean HVOC values in each percentile group are as follows: group 1: $940 \mu \mathrm{m}$; group 2: 1,128 $\mu \mathrm{m}$; group 3: 1,390 $\mu \mathrm{m}$; and group 4: 1,662 $\mu \mathrm{m}$ (Figure 6).

The mean (standard error [SE]) and 95\% confidence interval $(95 \% \mathrm{CI})$ of SAP MD in each HVOC percentile group are as follows: group 1: $-4.70(1.2) \mathrm{dB}(95 \%$ $\mathrm{CI}-7.1$ to -2.2$)$; group 2 : $-5.10(1.0) \mathrm{dB}(95 \% \mathrm{CI}-7.2$ to -2.9$)$; group 3: $-10.40(1.4) \mathrm{dB}(95 \% \mathrm{CI}-13.2$ to -7.6$)$; and group $4:-12.90(1.4) \mathrm{dB}(95 \% \mathrm{CI}-15.7$ to -10.0$)$.

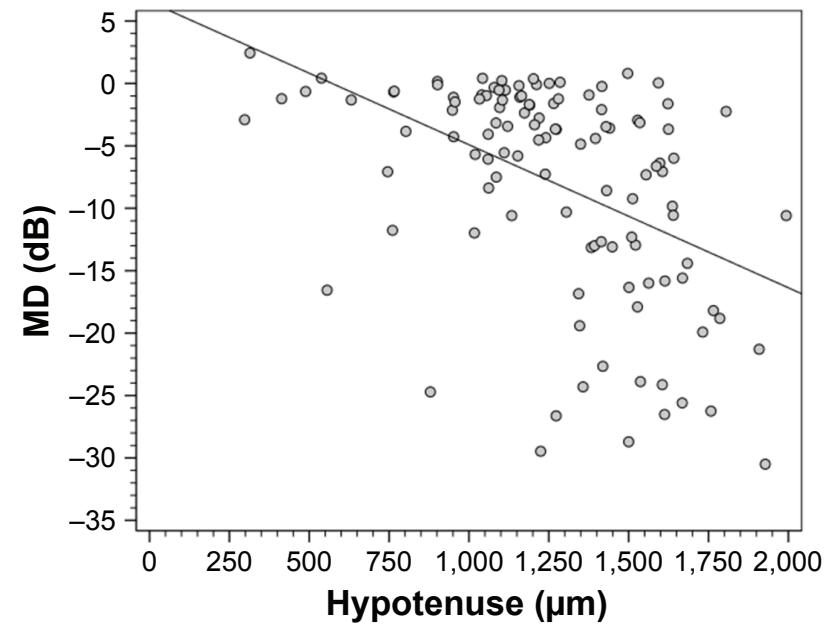

Figure 4 Scatter plot of the correlation between the mean deviation (MD) of standard automated perimetry and the hypotenuse of the vertical optic nerve head cup.

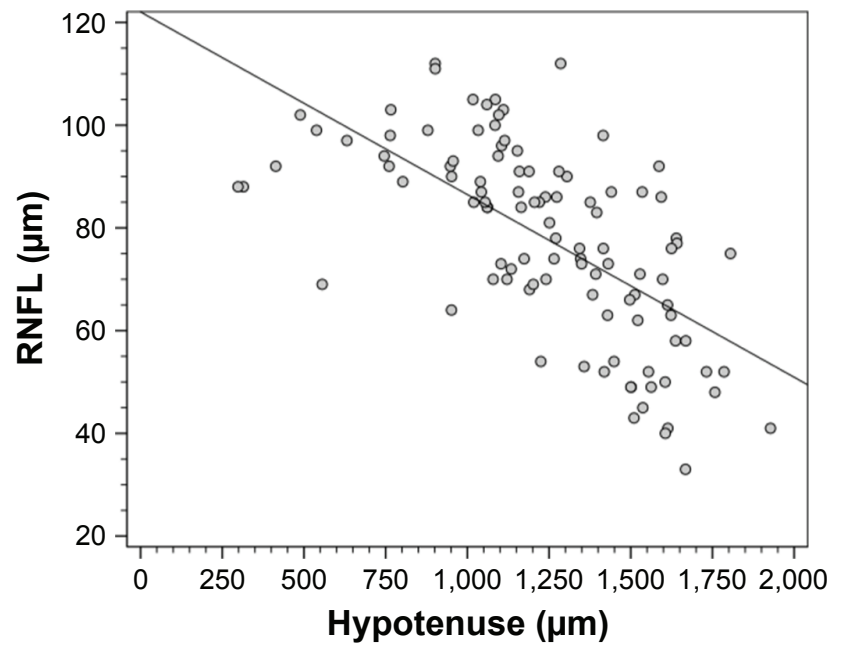

Figure 5 Scatter plot of the correlation between peripapillary retinal nerve fiber layer (RNFL) thickness measured by spectral-domain optical coherence tomography and the hypotenuse of the vertical optic nerve head cup.

There was a statistically significant difference in SAP MD between groups 1 and $3(P<0.03)$, groups 1 and $4(P<0.001)$, groups 2 and $3(P<0.02)$, and groups 2 and $4(P<0.001)$. A borderline significance was observed between groups 3 and $4(P<0.08)$ (Figure 7).

The mean (SE) and 95\% CI of RNFL thickness in each HVOC percentile group are as follows: group 1: 91.7 (2.5) $\mu \mathrm{m}$ (95\% CI 87.3-96.2); group 2: 83.2 (2.5) $\mu \mathrm{m}(95 \%$ CI 78.1-88.2); group 3: 71.1 (3.3) $\mu \mathrm{m}$ (95\% CI 64.6-72.6); and group 4: $62.6(2.97) \mu \mathrm{m}(95 \%$ CI 56.2-69.3). There were statistically significant differences between all groups: 1 versus $2(P<0.04)$; 1 versus $3(P<0.001) ; 1$ versus 4 $(P<0.001) ; 2$ versus $3(P<0.03) ; 2$ versus $4(P<0.001)$; and 3 versus $4(P<0.036)$ (Figure 8$)$.

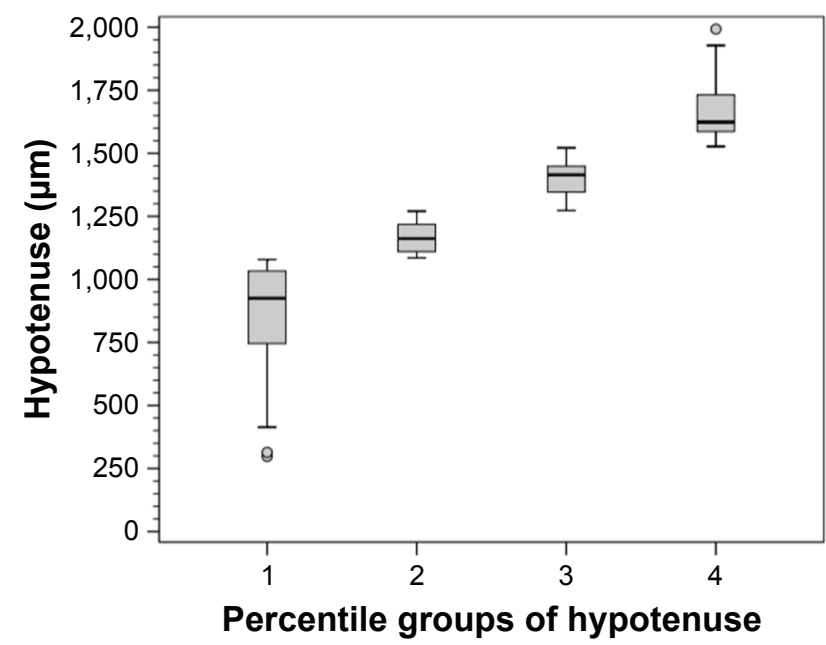

Figure 6 Box plot of the percentile groups of the hypotenuse of the vertical optic nerve head cup. 


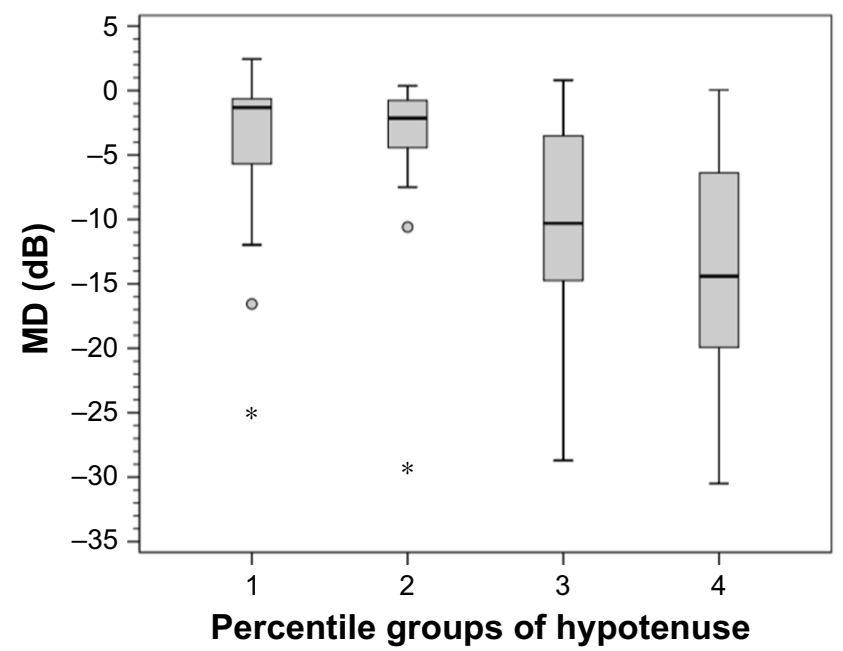

Figure 7 Box plot of the mean deviation (MD) of standard automated perimetry in each percentile group of the hypotenuse of the vertical optic nerve head cup. Note: *These are single more extreme outliers of the visual field MD values in this percentile.

Table 7 shows the distribution of eyes with glaucoma (MD $<$ and $\geq-7 \mathrm{~dB}$ ) and without glaucoma (controls) among HVOC percentile groups. The presence of controls was significantly higher in HVOC percentile group 1, while the presence of glaucoma with an MD worse than $-7 \mathrm{~dB}$ was significantly higher in percentile groups 3 and 4 .

Clinical examples of glaucomatous eyes in each HVOC percentile group are shown in Figures 9-12.

\section{Discussion}

The present study evaluated HVOC, a novel structural parameter for the multimodal assessment of glaucoma, using the EDI mode of the SD-OCT device. This mode has proven useful for in vivo morphological and morphometric

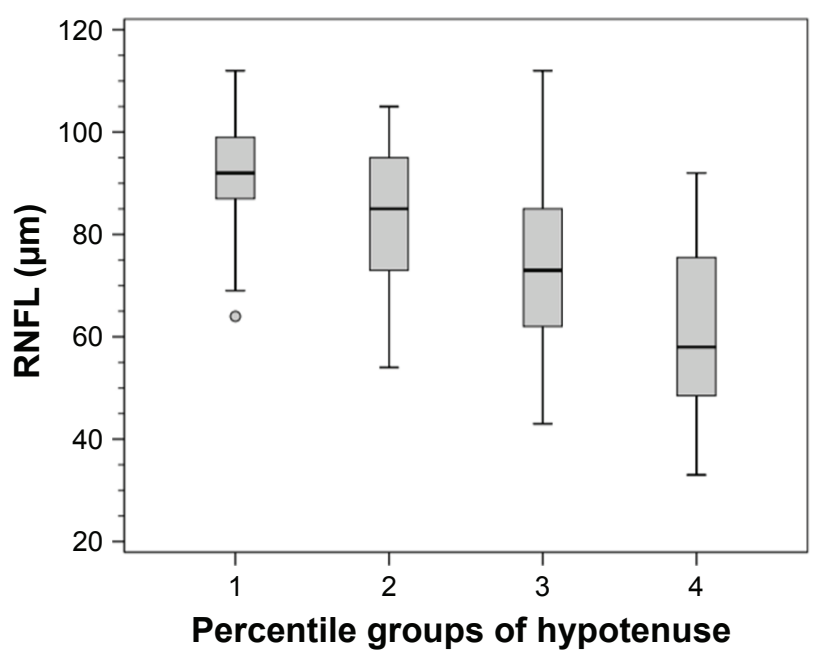

Figure 8 Box plot of circumpapillary retinal nerve fiber layer (RNFL) thickness measured by spectral-domain optical coherence tomography in each percentile group of the hypotenuse of the vertical optic nerve head cup.
Table 7 Distribution of eyes with and without glaucoma among the four percentile groups of the HVOC

\begin{tabular}{|c|c|c|c|c|}
\hline $\begin{array}{l}\text { HVOC } \\
\text { percentile } \\
\text { group }\end{array}$ & $\begin{array}{l}\text { Group I: } \\
\text { glaucoma } \\
\text { MD }<-7 \text { dB }\end{array}$ & $\begin{array}{l}\text { Group 2: } \\
\text { glaucoma } \\
\text { MD } \geq-7 \text { dB }\end{array}$ & $\begin{array}{l}\text { Group 3: } \\
\text { healthy eyes } \\
\text { (control) }\end{array}$ & Total \\
\hline I, n (\%) & $5(10.2)$ & $14(24.6)$ & II (78.6)* & $30(25)$ \\
\hline 2, n (\%) & $5(10.2)$ & $23(40.4)$ & $2(14.3)$ & $30(25)$ \\
\hline $3, \mathrm{n}(\%)$ & $18(36.7)^{* *}$ & $11(19.3)$ & I (7.I) & $30(25)$ \\
\hline 4, n (\%) & $21(42.9)^{* *}$ & $9(15.8)$ & $0(0)$ & $30(25)$ \\
\hline Total, n (\%) & $49(100)$ & $57(100)$ & $14(100)$ & $120(100)$ \\
\hline
\end{tabular}

Notes: *The number of controls in HVOC group I was significantly higher than in the other groups $(P<0.00 \mathrm{I})$. **The number of glaucomatous eyes with $M D<-7 \mathrm{~dB}$ in HVOC groups 3 and 4 was significantly higher than in groups $I$ and $2(P<0.00 I)$. Abbreviations: MD, mean deviation; HVOC, hypotenuse of the vertical optic nerve head cup.

analysis of deep ONH structures, including LC and adjacent structures. ${ }^{17,18}$ In the present sample, HVOC was significantly increased in glaucomatous eyes compared to normal eyes and in patients with more severe compared to less severe glaucoma. HVOC correlated well with structure (RNFL) and function (MD).

HVOC is a simple and easily reproducible parameter. The use of the eye-tracking system of SD-OCT ensures that the parameter will be obtained at the same location in multiple examinations. HVOC uses two important aspects of the excavation and remodeling of the glaucomatous $\mathrm{ONH}$ : depth of the cup, which may represent LC displacement due to increased IOP in susceptible eyes; and length of the cup, which corresponds to the neuroretinal rim thinning due to axonal loss that is also evaluated clinically.

Posterior LC displacement is a parameter that has been demonstrated histologically in experimental studies of glaucoma and in studies using postmortem glaucomatous eyes. ${ }^{33,34}$ Furlanetto et $\mathrm{al}^{28}$ showed that LC depth correlated functionally and was significantly greater in patients with glaucoma than in normal controls. Park et $\mathrm{al}^{27}$ evaluated the depth of posterior LC displacement by dividing the sample into different stages of glaucoma and found that LC depth was greater in patients with preperimetric glaucoma than in normal controls, and in mild-to-moderate glaucoma than in mild glaucoma. However, it was the difference between severe and mild-to-moderate glaucoma that was statistically significant. Jung et $\mathrm{a}^{35}$ showed that $\mathrm{LC}$ depth was associated with CDR in eyes with increased optic disc cupping and CDR asymmetry. In the present study, when the depth of the cup, as measured according to the method described here, was evaluated separately, significant differences were observed between normal eyes and glaucomatous eyes, but these differences were not significant between patients with milder glaucoma ( $\mathrm{MD} \geq-7 \mathrm{~dB}$ ) and more severe glaucoma $(\mathrm{MD}<-7 \mathrm{~dB})$. 
A

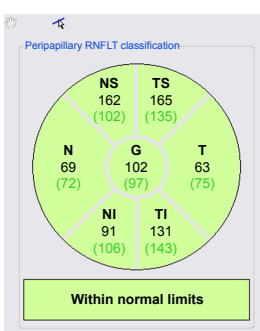

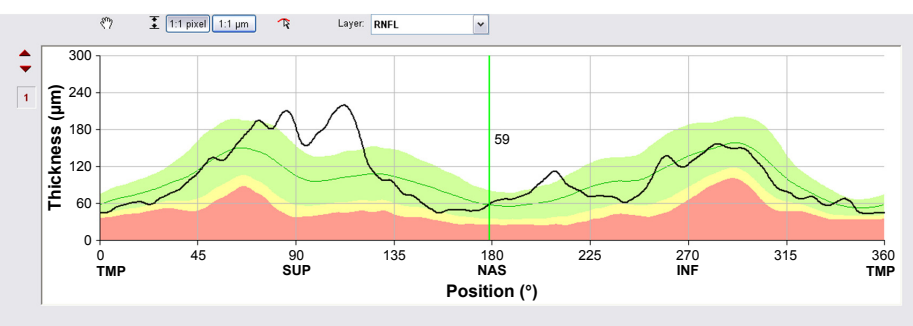

B
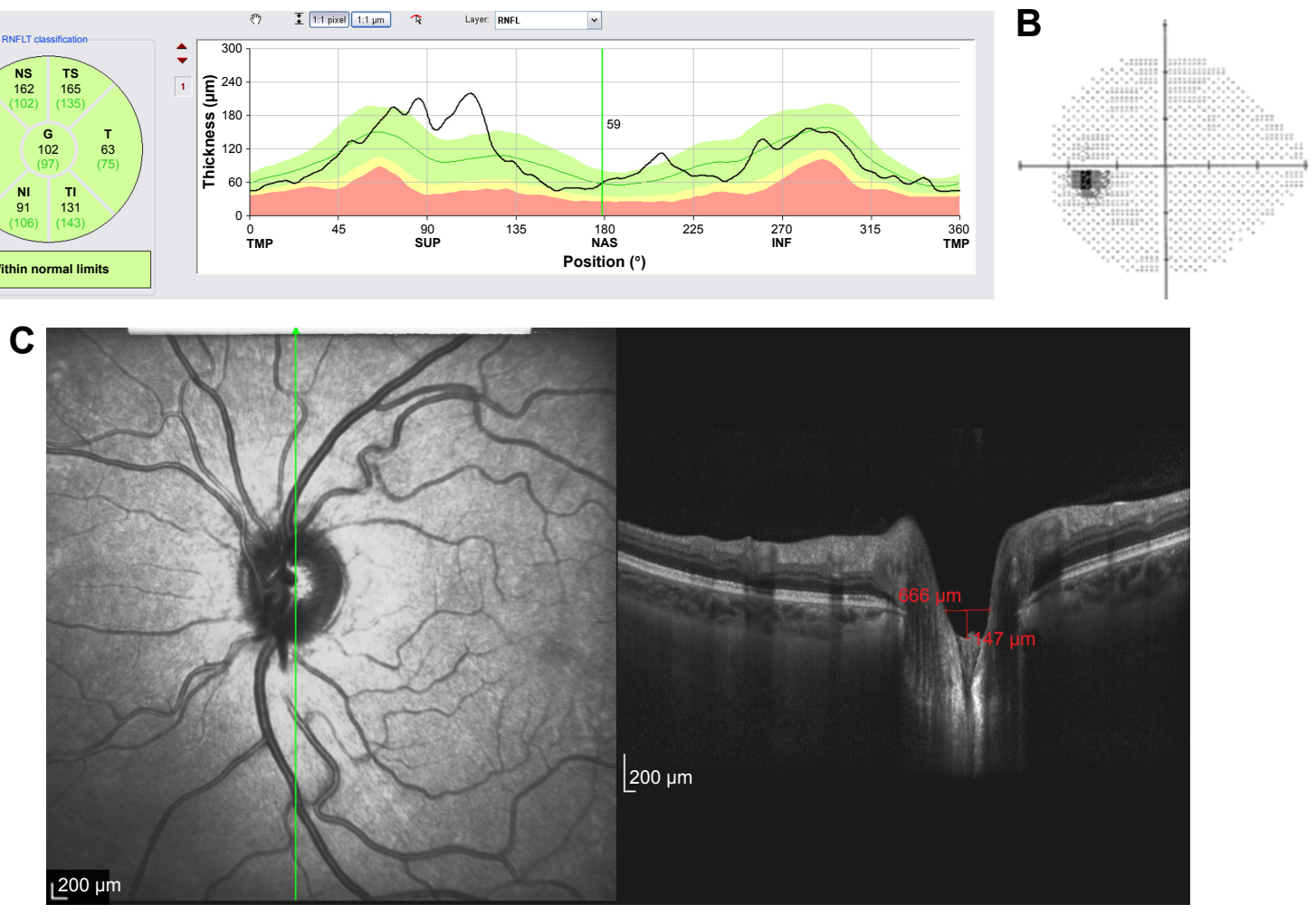

Figure 9 Structural and functional findings in a glaucomatous eye in percentile group I of the HVOC (mean $=940 \mu \mathrm{m}$, mean MD =-4.70 (I.2) dB). (A) Circumpapillary RNFLT; (B) standard automated perimetry grayscale map; (C) B-scan of the largest vertical optic disc cup and length and depth used to calculate the HVOC.

Abbreviations: HVOC, hypotenuse of the vertical optic nerve head cup; MD, mean deviation; RNFLT, retinal nerve fiber layer thickness.

A

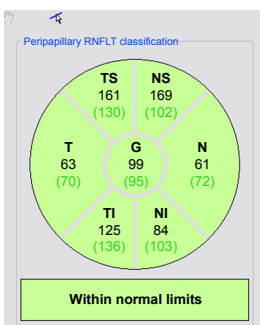

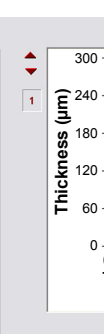

I. 1.1 pixal $11: 1 \mathrm{~mm}$ TF Layer RNFL

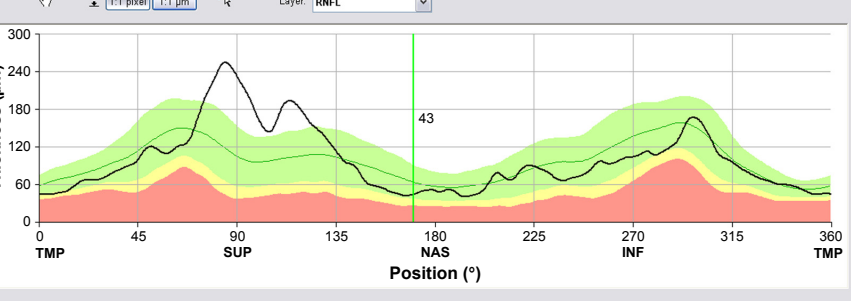

B

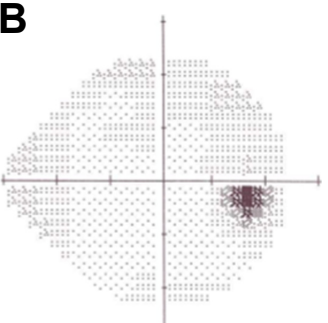

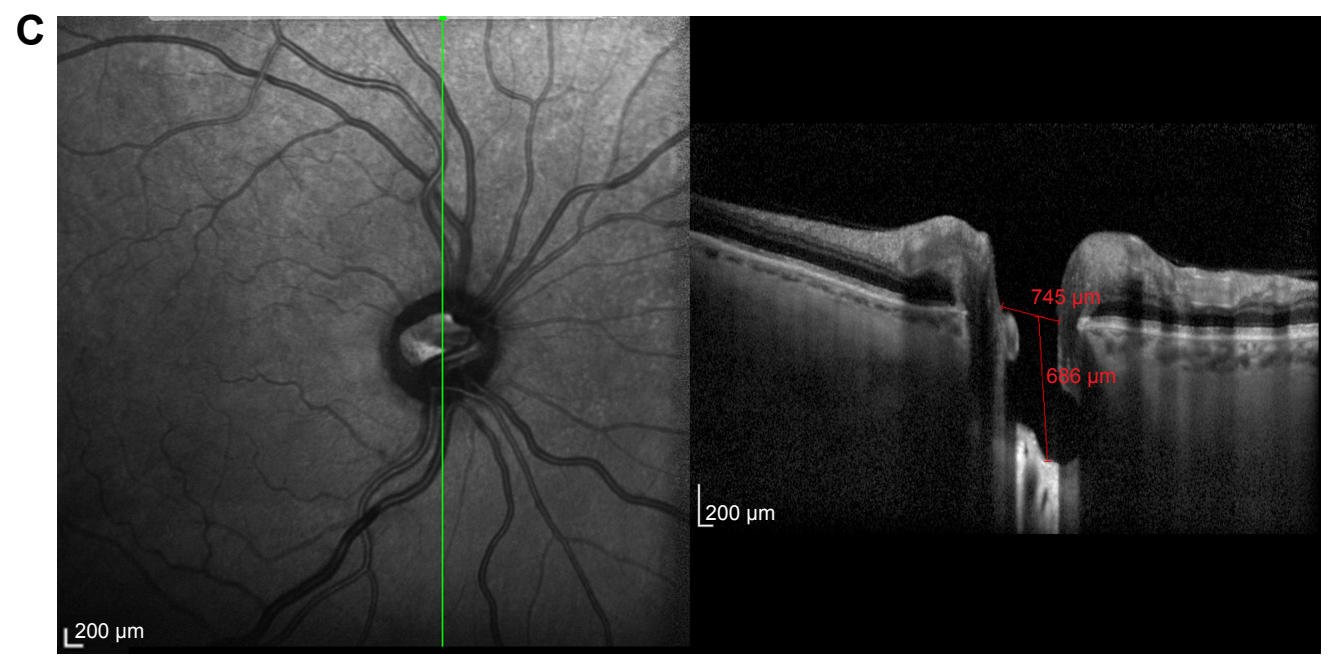

Figure 10 Structural and functional findings in a glaucomatous eye in percentile group 2 of the HVOC (mean =I, I28 $\mu \mathrm{m}$, mean MD =-5.10 (I.0) dB). (A) Circumpapillary RNFLT;

(B) standard automated perimetry grayscale map; (C) B-scan of the largest vertical optic disc cup and length and depth used to calculate the HVOC.

Abbreviations: HVOC, hypotenuse of the vertical optic nerve head cup; MD, mean deviation; RNFLT, retinal nerve fiber layer thickness. 
A

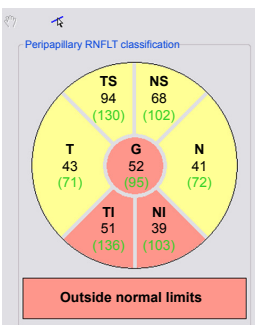

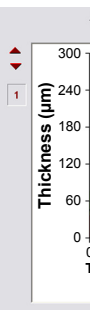

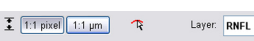

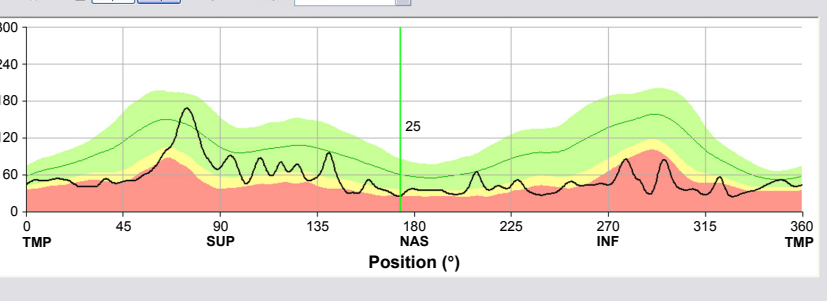

B

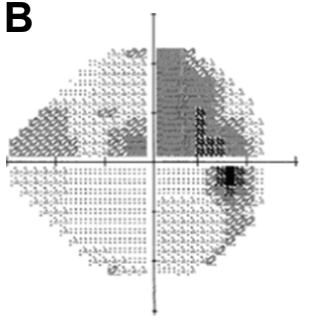

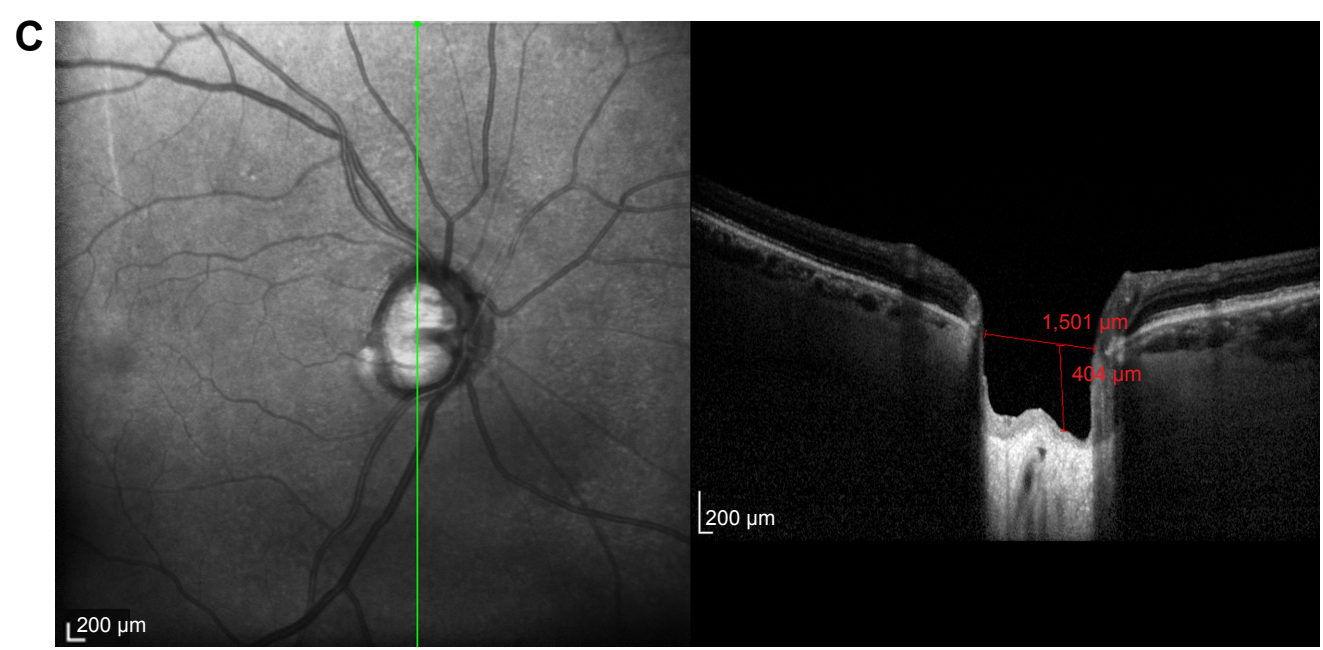

Figure I I Structural and functional findings in a glaucomatous eye in percentile group 3 of the HVOC (mean =I,390 $\mu \mathrm{m}$, mean MD =-I0.40 (I.4) dB). (A) Circumpapillary RNFLT; (B) standard automated perimetry grayscale map; (C) B-scan of the largest vertical optic disc cup and length and depth used to calculate the HVOC. Abbreviations: HVOC, hypotenuse of the vertical optic nerve head cup; MD, mean deviation; RNFLT, retinal nerve fiber layer thickness.
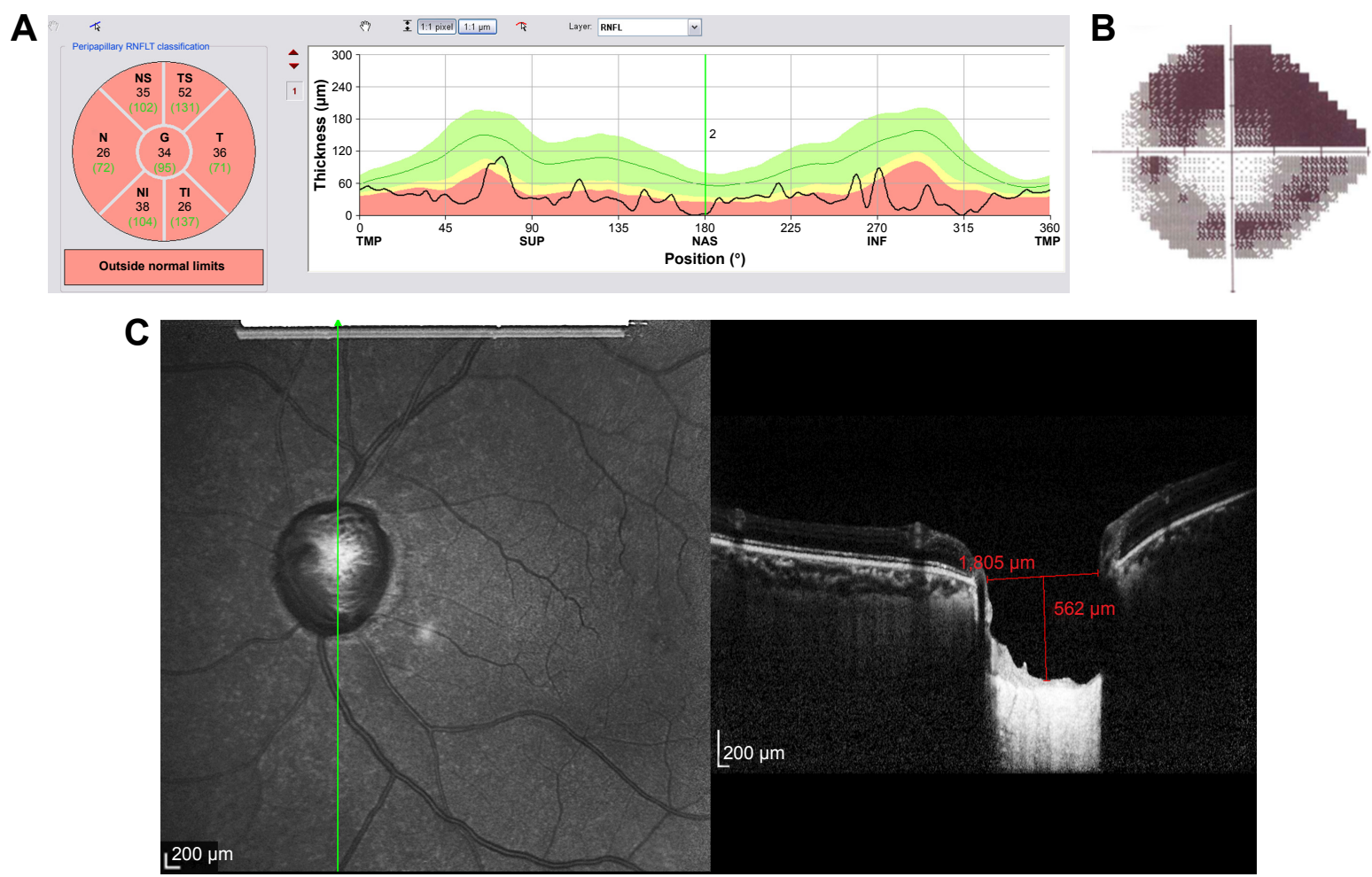

Figure I 2 Structural and functional findings in a glaucomatous eye in percentile group 4 of the HVOC (mean =I,662 $\mu$ m, mean MD =-I2.90 (I.4) dB). (A) Circumpapillary RNFLT; (B) standard automated perimetry grayscale map; (C) B-scan of the largest vertical optic disc cup and length and depth used to calculate the HVOC.

Abbreviations: HVOC, hypotenuse of the vertical optic nerve head cup; MD, mean deviation; RNFLT, retinal nerve fiber layer thickness. 
Prelaminar thinning is a component of plastic changes leading to the shallow form of excavation that results from the compression and/or loss of retinal ganglion cell axons. Prelaminar components may also be an important biomarker for the structural diagnosis of glaucoma. ${ }^{36-38}$ Chauhan and Burgoyne ${ }^{26}$ demonstrated that a clinically and stereophotographically visible rim margin disagrees with actual anatomical measurements using SD-OCT and BMO as an anatomical parameter to determine rim margin. Gardiner et $\mathrm{al}^{25}$ in a study describing rim measurements using BMO as a reference for the minimum rim width and area, reported that this parameter correlated functionally with $\mathrm{MD}$, but had a stronger correlation with RNFL thickness. In the present study HVOC also had a stronger correlation with RNFL thickness than with MD $(r=-0.47 ; P<0.001)$ in ONHs with a vertical diameter between $1.5-2.0 \mathrm{~mm}$. When eyes were divided according to percentile groups, based on HVOC values, these groups differed significantly from each other regarding RNFL thickness. As for MD, there were significant differences between percentile groups, except for group 1 versus 2 and a borderline correlation between groups 3 and 4 .

The usefulness of ONH parameters obtained with the Heidelberg Retina Tomograph and with OCT for the diagnosis of glaucoma and its progression has already been extensively studied. ${ }^{39-41}$ Lisboa et $\mathrm{al}^{42}$ reported that $\mathrm{ONH}$ parameters had receiver operating characteristic curves with smaller areas under the curve (AUC) than did RNFL thickness. However, among the ONH parameters, vertical CDR had the best AUC. Vertical CDR is a well-established clinical hallmark of glaucoma and a predictive factor for conversion from ocular hypertension to glaucoma. ${ }^{43}$ In the present study, the cup was measured vertically and used as one of the parameters to calculate the hypotenuse, and the length of the vertical cup was significantly different between glaucoma groups and controls.

Automated ONH parameters obtained with different devices must be checked for proper segmentation. There are many potential artifacts that may mislead the interpretation. In our study, HVOC was measured manually using the infrared image to determine the correct placement of the EDI B-scan over the largest portion of the vertical cup using the ART mode and eye-tracking system. SS-OCT, a current iteration of the OCT technology, permits deeper image penetration, obviating the need for EDI mode, and has a faster scanning speed, which, in prototype models, can reach over 400,000 scans/second. ${ }^{44}$ The principles for obtaining the HVOC and its components remain the same with SS-OCT.
The present study was conducted as a preliminary study to support the hypothesis that HVOC is a potential biomarker for the structural diagnosis of glaucoma. Further studies evaluating $360^{\circ} \mathrm{B}$-scans of the $\mathrm{ONH}$ and using not only the middle third of the cup, as in our method, but also the peripheral portions of the cup to measure depth should be performed. Average RNFL thickness was used as a structural parameter in our study. However, studying RNFL thickness in different regions (quadrants and clock-hour positions) in comparison with HVOC obtained in the corresponding portion of the $\mathrm{ONH}$ might increase the usefulness of information.

This study has some limitations. Different optic disc diameters and shapes might influence HVOC measurement. However, when discs were divided into different diameter ranges, significant differences were also observed between these groups, except for discs with a vertical diameter $<1.5 \mathrm{~mm}$, which showed no significant difference between glaucomatous eyes with MD worse and better than $-7 \mathrm{~dB}$. Future studies using HVOC, as well as other ONH parameters, should also consider disc size and phenotype as covariates. Optic discs with high myopic changes, chorioretinal scars, and large areas of peripapillary atrophy may be unsuitable for HVOC measurement. In our sample, there were no eyes with these findings. $\mathrm{MD}=-7 \mathrm{~dB}$ as the cutoff value to divide the glaucoma groups was arbitrary; however, between-group differences in MD and RNFL thickness were significant. This cutoff value was also significant when each HVOC percentile group was analyzed separately. The highest HVOC percentile had no normal eyes, while the lowest percentile (percentile groups 1 and 2) had only a few eyes (20.4\%) with an MD worse than $-7 \mathrm{~dB}(P<0.01)$.

HVOC may provide an additional morphometric parameter to detect $\mathrm{ONH}$ damage and remodeling, as it incorporates two important hallmarks: vertical length of the cup and depth of displacement. Moreover, HVOC measurement is simple and reproducible with the current OCT technology. Additional cross-sectional studies, as mentioned earlier, are required to further evaluate this parameter and its incorporation into the multimodal diagnosis of glaucoma using novel OCT technologies. Longitudinal studies are also required to assess the success of HVOC in detecting glaucoma progression and to compare HVOC with other structural and functional parameters.

\section{Acknowledgment}

This study was presented in part at the Association for Research in Vision and Ophthalmology Annual Meeting, 
Orlando, FL, USA, 2014, and at the Association for Research in Vision and Ophthalmology Annual Meeting, Seattle, WA, USA, 2016.

\section{Author contributions}

Conception and design, writing the article, and overall responsibility: Fabio Lavinsky and Paulo Augusto de Arruda Mello. Analysis and interpretation: Fabio Lavinsky. Data collection: Fabio Lavinsky, Nédio Castoldi, Camila Zanella Benfica, and Anne Elise Cruz do Carmo Chaves. All authors contributed toward data analysis, drafting and critically revising the paper, gave final approval of the version to be published, and agree to be accountable for all aspects of the work.

\section{Disclosure}

The authors report no conflicts of interest in this work.

\section{References}

1. Harwerth RS, Carter-Dawson L, Smith EL, Barnes G, Holt WF, Crawford ML. Neural losses correlated with visual losses in clinical perimetry. Invest Ophthalmol Vis Sci. 2004;45(9):3152-3160.

2. Gardiner SK, Johnson CA, Cioffi GA. Evaluation of the structurefunction relationship in glaucoma. Invest Ophthalmol Vis Sci. 2005; 46(10):3712-3717.

3. Anderson RS. The psychophysics of glaucoma: improving the structure/ function relationship. Prog Retin Eye Res. 2006;25(1):79-97.

4. Schuman JS, Hee MR, Puliafito CA, et al. Quantification of nerve fiber layer thickness in normal and glaucomatous eyes using optical coherence tomography. Arch Ophthalmol. 1995;113(5):586-596.

5. Baumal CR. Clinical applications of optical coherence tomography. Curr Opin Ophthalmol. 1999;10(3):182-188.

6. Budenz DL, Anderson DR, Varma R, et al. Determinants of normal retinal nerve fiber layer thickness measured by Stratus OCT. Ophthalmology. 2007;114(6):1046-1052.

7. Leung CK, Cheung CY, Weinreb RN, et al. Retinal nerve fiber layer imaging with spectral-domain optical coherence tomography: a variability and diagnostic performance study. Ophthalmology. 2009;116(7): $1257-1263$.

8. Asrani S, Rosdahl JA, Allingham RR. Novel software strategy for glaucoma diagnosis: asymmetry analysis of retinal thickness. Arch Ophthalmol. 2011;129(9):1205-1211.

9. Schuman JS. Spectral domain optical coherence tomography for glaucoma (an AOS thesis). Trans Am Ophthalmol Soc. 2008;106:426-458.

10. Leung CK, Cheung CY, Weinreb RN, et al. Evaluation of retinal nerve fiber layer progression in glaucoma: a study on optical coherence tomography guided progression analysis. Invest Ophthalmol Vis Sci. 2010; 51(1):217-222.

11. Bussel II, Wollstein G, Schuman JS. OCT for glaucoma diagnosis, screening and detection of glaucoma progression. Br J Ophthalmol. 2014;98(Supp1 2):15-19.

12. Wojtkowski M, Srinivasan V, Fujimoto JG, et al. Three-dimensional retinal imaging with high-speed ultrahigh-resolution optical coherence tomography. Ophthalmology. 2005;112(10):1734-1746.

13. Wojtkowski M, Srinivasan V, Ko T, Fujimoto J, Kowalczyk A, Duker J. Ultrahigh-resolution, high-speed, Fourier domain optical coherence tomography and methods for dispersion compensation. Opt Express. 2004;12(11):2404-2422.
14. Leung CK, Ye C, Weinreb RN, et al. Retinal nerve fiber layer imaging with spectral-domain optical coherence tomography: a study on diagnostic agreement with Heidelberg Retinal Tomograph. Ophthalmology. 2010;117(2):267-274.

15. Sander B, Larsen M, Thrane L, Hougaard JL, Jorgensen TM. Enhanced optical coherence tomography imaging by multiple scan averaging. Br J Ophthalmol. 2005;89(2):207-212.

16. Spaide RF, Koizumi H, Pozzoni MC. Enhanced depth imaging spectraldomain optical coherence tomography. Am J Ophthalmol. 2008;146(4): 496-500.

17. Park SC, De Moraes CG, Teng CC, Tello C, Liebmann JM, Ritch R. Enhanced depth imaging optical coherence tomography of deep optic nerve complex structures in glaucoma. Ophthalmology. 2012; 119(1):3-9.

18. Lee EJ, Kim TW, Weinreb RN, Park KH, Kim SH, Kim DM. Visualization of the lamina cribrosa using enhanced depth imaging spectral-domain optical coherence tomography. Am J Ophthalmol. 2011;152(1):87-95.

19. Potsaid B, Baumann B, Huang D, et al. Ultrahigh speed $1050 \mathrm{~nm}$ swept source/Fourier domain OCT retinal and anterior segment imaging at 100,000 to 400,000 axial scans per second. Opt Express. 2010;18(19): 20029-20048.

20. Stewart WC, Kolker AE, Sharpe ED, et al. Factors associated with long-term progression or stability in primary open-angle glaucoma. Am J Ophthalmol. 2000;130(3):274-279.

21. Jonas JB, Xu L. Optic disk hemorrhages in glaucoma. Am J Ophthalmol. 1994;118(1):1-8.

22. Martus P, Stroux A, Budde WM, Mardin CY, Korth M, Jonas JB. Predictive factors for progressive optic nerve damage in various types of chronic open-angle glaucoma. Am J Ophthalmol. 2005;139(6): 999-1009.

23. Harizman N, Oliveira C, Chiang A, et al. The ISNT rule and differentiation of normal from glaucomatous eyes. Arch Ophthalmol. 2006; 124(11):1579-1583.

24. Schuman JS, Wollstein G, Farra T, et al. Comparison of optic nerve head measurements obtained by optical coherence tomography and confocal scanning laser ophthalmoscopy. Am J Ophthalmol. 2003; 135(4):504-512.

25. Gardiner SK, Ren R, Yang H, Fortune B, Burgoyne CF, Demirel S. A method to estimate the amount of neuroretinal rim tissue in glaucoma: comparison with current methods for measuring rim area. Am J Ophthalmol. 2014;157(3):540-549.

26. Chauhan BC, Burgoyne CF. From clinical examination of the optic disc to clinical assessment of the optic nerve head: a paradigm change. Am J Ophthalmol. 2013;156(2):218-227.

27. Park SC, Brumm J, Furlanetto RL, et al. Lamina cribrosa depth in different stages of glaucoma. Invest Ophthalmol Vis Sci. 2015;56(3): 2059-2064.

28. Furlanetto RL, Park SC, Damle UJ, et al. Posterior displacement of the lamina cribrosa in glaucoma: in vivo interindividual and intereye comparisons. Invest Ophthalmol Vis Sci. 2013;54(7):4836-4842.

29. Ren R, Yang H, Gardiner SK, et al. Anterior lamina cribrosa surface depth, age, and visual field sensitivity in the Portland Progression Project. Invest Ophthalmol Vis Sci. 2014;55(3):1531-1539.

30. Bellezza AJ, Rintalan CJ, Thompson HW, Downs JC, Hart RT, Burgoyne CF. Deformation of the lamina cribrosa and anterior scleral canal wall in early experimental glaucoma. Invest Ophthalmol Vis Sci. 2003;44(2):623-637.

31. Yang H, Thompson H, Roberts MD, Sigal IA, Downs JC, Burgoyne CF. Deformation of the early glaucomatous monkey optic nerve head connective tissue after acute IOP elevation in 3-D histomorphometric reconstructions. Invest Ophthalmol Vis Sci. 2011;52(1):345-363.

32. Quigley HA, Hohman RM, Addicks EM, Massof RW, Green WR. Morphologic changes in the lamina cribrosa correlated with neural loss in open-angle glaucoma. Am J Ophthalmol. 1983;95(5):673-691. 
33. Yang H, Downs JC, Sigal IA, Roberts MD, Thompson H, Burgoyne CF. Deformation of the normal monkey optic nerve head connective tissue after acute IOP elevation within 3-D histomorphometric reconstructions. Invest Ophthalmol Vis Sci. 2009;50(12):5785-5799.

34. Yan DB, Coloma FM, Metheetrairut A, Trope GE, Heathcote JG, Ethier CR. Deformation of the lamina cribrosa by elevated intraocular pressure. Br J Ophthalmol. 1994;78(8):643-648.

35. Jung KI, Jeon S, Park CK. Lamina cribrosa depth is associated with the cup-to-disc ratio in eyes with large optic disc cupping and cup-to-disc ratio asymmetry. J Glaucoma. 2016;25(5):e536-e545.

36. Yang H, Downs JC, Burgoyne CF. Physiologic intereye differences in monkey optic nerve head architecture and their relation to changes in early experimental glaucoma. Invest Ophthalmol Vis Sci. 2009;50(1): 224-234.

37. Burgoyne CF, Downs JC, Bellezza AJ, Suh JK, Hart RT. The optic nerve head as a biomechanical structure: a new paradigm for understanding the role of IOP-related stress and strain in the pathophysiology of glaucomatous optic nerve head damage. Prog Retin Eye Res. 2005;24(1): 39-73.

38. Burgoyne CF, Downs JC. Premise and prediction - how optic nerve head biomechanics underlies the susceptibility and clinical behavior of the aged optic nerve head. J Glaucoma. 2008;17(4):318-328.
39. Wollstein G, Garway-Heath DF, Hitchings RA. Identification of early glaucoma cases with the scanning laser ophthalmoscope. Ophthalmology. 1998;105(8):1557-1563.

40. Gordon MO, Beiser JA, Brandt JD, et al. The Ocular Hypertension Treatment Study: baseline factors that predict the onset of primary open-angle glaucoma. Arch Ophthalmol. 2002;120(6):714-720.

41. Medeiros FA, Vizzeri G, Zangwill LM, Alencar LM, Sample PA, Weinreb RN. Comparison of retinal nerve fiber layer and optic disc imaging for diagnosing glaucoma in patients suspected of having the disease. Ophthalmology. 2008;115(8):1340-1346.

42. Lisboa R, Paranhos A Jr, Weinreb RN, Zangwill LM, Leite MT, Medeiros FA. Comparison of different spectral domain OCT scanning protocols for diagnosing preperimetric glaucoma. Invest Ophthalmol Vis Sci. 2013;54(5):3417-3425.

43. Ocular Hypertension Treatment Study Group, European Glaucoma Prevention Study Group, Gordon MO, et al. Validated prediction model for the development of primary open-angle glaucoma in individuals with ocular hypertension. Ophthalmology. 2007;114(1):10-19.

44. Yang Z, Tatham AJ, Zangwill LM, Weinreb RN, Zhang C, Medeiros FA. Diagnostic ability of retinal nerve fiber layer imaging by sweptsource optical coherence tomography in glaucoma. Am J Ophthalmol. 2015;159(1):193-201.
Clinical Ophthalmology

\section{Publish your work in this journal}

Clinical Ophthalmology is an international, peer-reviewed journa covering all subspecialties within ophthalmology. Key topics include: Optometry; Visual science; Pharmacology and drug therapy in eye diseases; Basic Sciences; Primary and Secondary eye care; Patien Safety and Quality of Care Improvements. This journal is indexed on

Submit your manuscript here: http://www.dovepress.com/clinical-ophthalmology-journal

\section{Dovepress}

PubMed Central and CAS, and is the official journal of The Society of Clinical Ophthalmology (SCO). The manuscript management system is completely online and includes a very quick and fair peer-review system, which is all easy to use. Visit http://www.dovepress.com/ testimonials.php to read real quotes from published authors. 